\title{
Whence and Whither the PfP Consortium?
}

\section{Frederic Labarre *}

The PfP Consortium is already a full ten years old. The time has come to look back on the road it has traveled, and to anticipate what lies on the road ahead. This essay will dwell upon the most significant achievements of the Consortium (in my eyes), as well as upon some shortcomings.

In doing so, it is useful to reflect on the notion of "PfP." This shorthand method of referring to both partnership and peace obscures the meaning of these two very powerful words. As a "Partnership," the Consortium requires the input of a variety of actors, and in this regard the support staff at the Marshall Center deserves most of the credit, as do the countries that have been generous with both their funding and logistical support over the years. Clearly, the United States, Switzerland, Germany, and Austria deserve most of the credit here.

But the notion of "Peace" brings into focus the actions of those countries, institutions, and individuals for whom the Consortium was intended. The PfP nations of ten years ago-many of whom are now members of NATO and/or the EU-have been indirectly led into the larger process of integration through the willingness of their institutions to interact with partner institutions in other countries. For the directors and project managers in these academies, institutes, and ministries, this has required an inordinate amount of faith and moral courage. Discovering and displaying the moral courage necessary to shed the established views and the momentum of habits of fifty (if not (seventy) years of Cold War has been difficult indeed, even on the "Western" side of the equation.

In this respect, the successes that have been achieved are partial, but still significant. In the case of the South East Europe, the catastrophe brought on in the Balkans by the disintegration of the former Yugoslavia had to be stopped by UN and allied intervention on two occasions since the end of the Cold War, in Bosnia and Kosovo. But this did not keep representatives from various factions from meeting in the halls of Reichenau Castle every spring (at the workshops held by the PfP Study Group on "Regional Stability in South East Europe") to discuss, mostly constructively, the challenges of peace. Although the actors present at these meetings rarely had the power or authority to enforce any decisions that might have arisen from the spring discussions in Austria, an indirect influence was achieved by demonstrating what decades of peace could achieve, with the right mix of civic responsibility, tolerance, and accountability.

Looking at the success of the Regional Stability in South East Europe Study Group, I do believe that we can identify certain elements of success. The first element is the commitment of a nation to host such an event in a recurring, predictable manner, championed by an expert team of organizers, and also supported by actors from the re-

Frederic Labarre is Head of Department of Political and Strategic Studies at the Baltic Defence College in Tartu, Estonia. 
gion. The supervision and attention to detail on the part of the event organizers ensures that participants will be able to focus freely on the issues at stake. Most importantly, however, the presence of actors from the region ensures the legitimacy of the process. This sort of legitimacy, buttressed by genuine academic support, is a cornerstone of success. Too often, "Westerners" have been accused of lecturing when they should be listening. This charge of proselytism is harder to level against individuals who are from the region under discussion, however. Integration into a community of diverse and challenging views is that much more readily accomplished when "one of your own" (if we must use these terms) is seen as being fully "integrated."

Another element of success has to do with the understanding that human beings and institutions-especially those that are operating under the stress of being forced to define a new identity because of the emergence of new states, and the disintegration of old ones-are fundamentally proud, and thus are reluctant to publicly discuss the sensitive core of the issue. The Study Group has attempted to compensate for this human character flaw by offering as many opportunities for face-to-face discussions that take place away from the scrutiny of the editor of the conference proceedings.

North Americans are normally impatient, and I am no different. Many of us may have chafed at the thought that no "project" or deliverable seemed to emerge from certain working groups. Unfortunately for North Americans, we can rarely assume that we have the luxury of pursuing a program that takes the long view. The Austrian National Defence Academy has provided support for nearly the last ten years to ensure that the RSSEE conferences can take place every spring in Reichenau, Austria. Because of this long-term support, one can evaluate (through the published conference proceedings) the ways in which the topic of the conferences has evolved through the years. If 2001 was dominated by the question of the Presevo Valley and Kosovar Albanian incursions into Macedonia, the 2003 meetings held in Dubrovnik, Croatia, were focused on the link between crime and economic development. The fact that the topics of the discussions at these meetings moved away from contentious matters of sovereignty and boundaries and toward narrow social issues with more long-term influence on peace in the Balkans is a sign of the maturity emerging in the region, which is felt but also indirectly fed by the organizers of the conferences in Austria, Croatia, and Bulgaria. This evolution is a deliverable that demonstrates the regional success of the Study Group and the broader impact of the PfP Consortium.

Austria and Switzerland, through the Centre for the Democratic Control of Armed Forces (DCAF) in Geneva, have attempted to provide a similar long-term schedule of meetings and workshops focused on the issue of civil control of security services for actors from the Black Sea area and the Caucasus. While the achievements in this regard were less tangible that in the case of South East Europe, I fondly remember a meeting in 2003, where I was privileged to the reaction of Georgian participants to the Rose Revolution taking place in their country at the same time that Austria was hosting a working group on the Caucasus. The effect here was to bring into perspective the very reason for the PfP Consortium's existence: it was designed to help those who were in charge of managing situations of great change. It has been five years since the Rose Revolution, and now it is Armenia that is in the throes of fundamental change. To 
those who may have doubted the validity of such a forum, the lessons of Georgia in 2003 and Armenia at the moment I write these lines are potent reminders that change is best handled by talking, and not fighting, and that therefore, the PfP Consortium's job is not over.

The Caucasus Working Group found itself fused with a working group devoted to the emergent Black Sea area, and the combined body was soon incorporated into the Romanian defense university. Its inaugural conference, held in Bucharest in JanuaryFebruary 2006, demonstrated to all doubters that the organizers had a precise plan for how they wanted to manage this working group. As a result of this clarity, the organizers were able to elevate the number of participants, as well as to increase the range of the participants in terms of specialization. The fact that Russian admirals, Turkish diplomats, Georgian ambassadors, and Romanian parliamentarians were at the same table discussing issues related to the future use of the Black Sea and the potential creation of a Black Sea defense college with academics from Germany and the U.S. and officials from NATO (among many others) leaves no doubt that the PfP Consortium is capable of attracting attention in the highest decision-making circles, and that officials of high stature can have confidence in the discussion of matters with important stakes that take place within a context of relative informality. To the creators of the PfP Consortium, the fact that Romania was taking ownership of such an important strategic forum demonstrated the depth of the success of the Consortium's integration processes and the commitment of its participants.

Other working groups, such as the Military History Working Group, may have been treated less fairly. Due to budgetary pressures, the Military History Working Groupwhich has by far the highest "entertainment” value, or ability to generate broader interest - had to be cut, but its value was such that it continued to attract the interest of various participants. The last meeting, held in Kingston, Ontario in March 2007, took place outside the rubric of the PfP Consortium, but reunited participants from Austria, Canada, France, Romania, Slovakia, and the United States, to name just a few. The contribution of the Military History Working Group to the parallel history of the Cold War should also be understood as an essential milestone in the process of great power reconciliation, and I can testify that the example of this contribution was often put forward as a practical measure of confidence building in the Balkans. What the Balkans need, among many other important things, is a common understanding of history. Lest we forget, it is difficult for many of us to make sense of where we are going by forgetting where we came from. The Regional Stability in South East Europe Study Group, piloted by our Austrian colleagues, continues to promote this shared understanding.

When we speak of tangible deliverables, none rivals (in the North American mind, at least) those of the Advanced Distributed Learning Working Group. Here, the contributions of Germany, Switzerland, the Ukraine, and the United States shine particularly brightly. The aim of the ADL Working Group is to bring together technicians and practitioners (some from as far away as Australia) to set up processes and tools for developing and hosting online courses for the benefit of the other working groups, academies, and institutions. Here, the discussions have been decidedly less political and more technical in nature. No one can discount the impact that the ADL Working Group 
has had in stimulating work and exploration of novel training and education delivery techniques and tools in the NATO world. Today, the NATO Defense College in Rome and the NATO School in Oberammergau, Germany both use courses designed through the interaction of the various working groups to bring greater efficiency to the delivery of their onsite curricula. Hungary, Poland, and Romania now all embrace the benefits of ADL in the development of their armed forces, following the examples of Canada, Sweden, and the United States.

The impact of the ADL Working Group's achievements is testimony to the group's commitment to excellence and to the continued refinement of the product (an improvement process that has taken place perhaps to the chagrin of those of us who are less technologically inclined). This has led some to believe that perhaps most (if not all) military training and education could be replaced by ADL. This is clearly not the case, and those of us who deal with such issues have to constantly engage those who believe it to be true on the one hand, and those who fear that it will come true, on the other hand. Clearly, the working group should perhaps communicate better to the noninitiated what the potential for ADL is. ADL is a medium that, when misused, can stifle academic freedom rather than stimulate it. This is why I believe that future meetings of the ADL Working Group should deal less with the technicalities of the instrument, and focus more on how to bring it to bear in a responsible manner. Perhaps the creation of a peer-review panel to vet new courses would be in order, but I will leave that issue to the chair of the ADL Working Group.

But so much for the past. Where are we going now? I must observe with much regret that the country (and the attendant institutions) that was most in need of engagement-Russia—is not as present within our working groups and study groups as would be hoped. In my eight years of involvement with the PfP Consortium, I have met only six Russian nationals. Lately, the family of publications has dropped Russian as a language of translation, which I believe is a real tragedy, if only for those citizens in other countries who are more comfortable with this language than they are with English. Again, budgetary pressures are to blame, but the paucity of interest emanating from Russian institutions is also a cause.

At a moment when Russia is emerging once again as a global player, forums such as the PfP Consortium, where discussions deal with significant issues in an informal manner, are needed more than ever. There is a feeling that the general trend in foreign policy-making in the U.S.-more concerned with the Middle East than with Central and Eastern Europe-has clearly been detrimental to the PfP Consortium. But, as an officer working for the Office of the U.S. Secretary of Defense has confided, regardless of who holds the key to the White House in November 2008, one can be assured of a greater spirit of cooperation with Europe in the wake of the travails of the United States in Afghanistan and Iraq. Coming from the most generous funding agent of the PfP Consortium, this bodes rather well for the future.

But resources are not the only issue. Much needs to be done to help make the EuroAtlantic arena fully peaceful and functional; the work in Kosovo is clearly not complete, and the developments there could have a reverse effect in Bosnia, now that SFOR has yielded to EUFOR, which is conducting mostly police activities that are less 
coercive in nature. Reforms in Georgia are under pressure by secessionist impulses and by the influence of neighboring states. Ukraine and Croatia may be standing ready to join NATO, but in some cases in may be true that the message that the Alliance intends to convey is being misconceived in the potential member states (just as it is being misperceived in Russia). Clearly, more integration is needed.

Armenia's domestic situation is also tense. The situations in Nagorno-Karabakh and in Transnistria remain frozen because policy attention has been drawn away by the spectacular actions by millionaire terrorist miscreants. At a moment when energy policy has had so powerful an adverse impact on years of work on "good-neighborly relations," shouldn't the PfP Consortium seek to consolidate the successes of the past decade in a way to effect constructive policy-making in the region for all involved (indirectly, if need be)? Shouldn't there be an Energy Security Working Group under the PfP umbrella? All these matters remain for the next ten, twenty, or perhaps thirty years. These subjects should clearly be the focus of more than the occasional paper in Connections.

And certainly, special overtures should be made to Russia. More has to be done within the PfP Consortium to promote cordial relations with this great country, perhaps including re-issuing Connections in Russian. At a moment when Russia's representatives will be invited to attend the NATO Summit in Bucharest, the least that the PfP Consortium can do to welcome with open arms those who, in my estimation at least, have the greatest interest in sharing their concerns and priorities in the spirit of cooperation should define the twenty-first century, rather than the realpolitik habits of the nineteenth century, to which our countries are always at risk of returning. 